www.jmscr.igmpublication.org

Index Copernicus Value: 79.54

ISSN (e)-2347-176x ISSN (p) 2455-0450

crossref DOI: https://dx.doi.org/10.18535/jmscr/v7i4.13

Journal Of Medical Science And Clinical Research

IGM Publication

An Official Publication of IGM Publication

\title{
Surgical factors affecting superficial surgical site infections in laparotomy incisions
}

\author{
Authors \\ Dr Abdul Basith P.T ${ }^{1}$, Dr Sanaa Mohammed Konnakkodan ${ }^{2}$ \\ ${ }^{1}$ Assistant Professor, General Surgery, Govt Medical College Kozhikode, India \\ Ph:+919037952205, Email: drabpt@gmail.com \\ ${ }^{2}$ Assistant Professor, Government Medical College, Kozhikode, India \\ Ph: +917293851717, Email: sanaabasith@gmail.com
}

\begin{abstract}
Aim: to compare incidence of superficial surgical site infections in elective and emergency laparotomies and to study the significance of factors like duration of surgery and level of contamination in incidence of superficial SSI

Materials and Methods: 200 patients who underwent midline laparotomy (100 patients each in elective and emergency laparotomy groups) were followed up for a period of one month for the incidence of surgical site infections and effect of surgical risk factors were analysed

Results: the incidence of superficial surgical site infections was $20.7 \%$ with a higher incidence in those who underwent emergency laparotomy. surgical site infections were higher among patients who underwent prolonged surgeries, higher level of contamination was associated with higher incidence of superficial SSI

Keywords: superficial surgical site infections, elective and emergency laparotomy, duration of surgery, level of contamination.
\end{abstract}

\section{Introduction}

Post operative infections increases both surgical morbidity and mortality and increases the duration of hospital stay and overall medical expense. We studied the role of factors like duration of surgery and level of microbial contamination in predicting the incidence of superficial surgical site infection

\section{Objective}

To study the surgical factors predicting the incidence of surgical site infections after elective and emergency laparotomy

\section{Specific Objectives}

- To compare the incidence of superficial surgical site infections following elective and emergency laparotomy

- To study the statistical significance of factors like duration of surgery and level of microbial contamination in predicting incidence of superficial surgical site infections

\section{Materials and Methods}

This was a prospective observational study conducted at a tertiary care hospital after 
obtaining permission from institutional ethics committee. 200 patients who underwent laparotomy through a midline incision in the age group 18-70 years during the study period of four months were incorporated into the study. Patients not willing to participate and those who developed deep incisional and organ space infections and those who expired before completion of study period were excluded from the study. Of the 200 subjects, 100 underwent laparotomy as an emergency procedure and the other 100 underwent laparotomy on an elective basis. The patients were examined postoperatively on day 1 , day8, day 15 and day30 for the presence of superficial surgical site infections.

Surgical site infection was diagnosed based on criteria laid down by Centre for disease control (CDC). Data was recorded in a questionnaire and was analysed using SPSS software. the data was analysed for effect of factors like duration of surgery and level of microbial contamination. Variables were compared using statistical tests including chi-square analysis and relative risk calculation.

\section{Results}

The subjects were divided into two groups based on whether laparotomy was done as an emergency or elective procedure. The two groups were age and sex matched. The mean age was $49.44 \pm 16$ in those who underwent emergency procedure and $51.88 \pm 10$ in those who underwent elective procedures.

The incidence of superficial surgical site infections in the study group was $20.5 \%$. Among the patients who underwent laparotomy as an emergency procedure 27 patients (27\%) developed surgical site infections where as 14 patients (14\%) among those who underwent laparotomy on an elective basis developed surgical site infection ( $\mathrm{P}$ value 0.023 )We found a significant increase in incidence of surgical site infections in the group with emergency laparotomy with a relative risk of 1.929(1.0773.455)

Prolonged surgeries with a duration more than 2 hours showed an increased incidence of SSI but was statistically significant only in elective laparotomy group

Table 1 Incidence of superficial SSI according to duration of surgery

\begin{tabular}{|c|c|c|c|c|c|c|}
\hline & \multicolumn{2}{|c|}{$\begin{array}{l}\text { Emergency } \\
\text { laparotomy }\end{array}$} & \multicolumn{2}{|c|}{$\begin{array}{c}\text { Elective } \\
\text { laparotomy }\end{array}$} & \multicolumn{2}{|c|}{$\begin{array}{c}\text { all } \\
\text { cases }\end{array}$} \\
\hline $\begin{array}{l}\text { Operating } \\
\text { time }\end{array}$ & Upto 2 hours & $\begin{array}{c}\text { More than } 2 \\
\text { hours }\end{array}$ & Upto 2 hours & $\begin{array}{c}\text { More than } 2 \\
\text { hours }\end{array}$ & $\begin{array}{c}\text { Upto two } \\
\text { hours }\end{array}$ & $\begin{array}{l}\text { More than } \\
\text { two hours }\end{array}$ \\
\hline SSI+ & $\begin{array}{c}20 \\
27.0 \%\end{array}$ & $\begin{array}{c}7 \\
26.9 \%\end{array}$ & $\begin{array}{c}2 \\
4 \% \\
\end{array}$ & $\begin{array}{c}12 \\
24 \% \\
\end{array}$ & $\begin{array}{c}22 \\
17.7 \% \\
\end{array}$ & $\begin{array}{c}19 \\
25.0 \% \\
\end{array}$ \\
\hline SSI- & $\begin{array}{c}54 \\
73 \%\end{array}$ & $\begin{array}{c}19 \\
73.1 \%\end{array}$ & $\begin{array}{c}48 \\
96 \%\end{array}$ & $\begin{array}{c}38 \\
76 \%\end{array}$ & $\begin{array}{c}102 \\
82.3 \%\end{array}$ & $\begin{array}{c}57 \\
75 \%\end{array}$ \\
\hline$P$ value & \multicolumn{2}{|c|}{0.992} & \multicolumn{2}{|c|}{0.003} & \multicolumn{2}{|c|}{0.217} \\
\hline Relative risk & \multicolumn{2}{|c|}{$0.996(2.07-0.477)$} & \multicolumn{2}{|c|}{$5.98(25.64-1.414)$} & \multicolumn{2}{|c|}{$1.408(2.427-0.818)$} \\
\hline
\end{tabular}

Incidence of superficial surgical site infections contamination. Contaminated wounds showed also increased with increasing levels of maximum incidence of surgical site infections

Table 2 Incidence of surgical site infections according to level of contamination

\begin{tabular}{|l|c|}
\hline Level of microbial contamination & Incidence of superficial surgical site infection \\
\hline clean & $1(7.1 \%)$ \\
\hline Clean contaminated & $7(8 \%)$ \\
\hline contaminated & $12(35.3 \%)$ \\
\hline dirty & $21(32.3 \%)$ \\
\hline total & $41(20.5 \%)$ \\
\hline
\end{tabular}

$$
\text { P Value - } 0.000
$$

For the calculation of relative risk and for comparing the predictive value of level of microbial contamination across elective and emergency laparotomy, clean and clean contaminated surgeries were grouped together and contaminated and dirty surgeries were grouped together and analysed 
Table 3

\begin{tabular}{|l|c|c|c|c|c|c|}
\hline & \multicolumn{2}{|c|}{ Elective laparotomy } & \multicolumn{2}{c|}{ Emergency laparotomy } & \multicolumn{2}{c|}{ All cases } \\
\hline & SSI + & SSI- & SSI+ & SSI- & SSI+ & SSI- \\
\hline $\begin{array}{l}\text { Clean and clean } \\
\text { contaminated }\end{array}$ & 5 & 67 & 3 & 26 & 8 & 93 \\
\hline $\begin{array}{l}\text { Contaminated and } \\
\text { dirty }\end{array}$ & $6.9 \%$ & $93.1 \%$ & $10.3 \%$ & $89.7 \%$ & $7.9 \%$ & $92.1 \%$ \\
\hline P value & $32.1 \%$ & $67.9 \%$ & $33.8 \%$ & $66.2 \%$ & $33.3 \%$ & $66.7 \%$ \\
\hline Relative risk & \multicolumn{2}{|c|}{0.001} & \multicolumn{2}{|c|}{0.017} & \multicolumn{2}{c|}{0.000} \\
\hline
\end{tabular}

\section{Discussion}

Surgical site infections (SSIs) are the most prevalent surgical wound complications, comprising approximately $15 \%$ of all health careassociated infections ${ }^{1}$. Surgical site infections have been defined by Center for Disease Control ${ }^{2}$ which divided them into superficial incisional, deep incisional and organ space infections. Our study covers only superficial incisional surgical site infections which are defined as Infection occurring within 30 days after the operation and infection involving only skin and subcutaneous tissue of the incision and at least one of the following:

1) Purulent drainage with or without laboratory confirmation, from the superficial incision

2) Organisms isolated from an aseptically obtained culture of fluid or tissue from the superficial incision

3) At least one of the following signs or symptoms of infection: pain or tenderness, localised swelling, redness, or heat and superficial incision is deliberately opened by surgeon, unless incision is culturenegative

4) Diagnosis of superficial incisional SSI made by a surgeon or attending physician

While the global estimates of surgical site infection (SSI) have varied from $0.5 \%$ to $15 \%$, studies in India have consistently shown higher rates ranging from $23 \%$ to $38 \%{ }^{3}$. Our study showed an incidence of SSI in $20.5 \%$ of total study group. SSI incidence was $27 \%$ in group which underwent emergency laparotomy and $14 \%$ in those who underwent elective laparotomy.
Study by Kumar A et $\mathrm{al}^{4}$ showed that SSI was associated with $17.7 \%$ of emergency surgeries as compared to $12.5 \%$ of elective surgeries.

In a study by Kamat US et $\mathrm{al}^{5}$ a higher SSI rate of $30.7 \%$ was found.

The overall incidence of surgical site infection (SSI) has been estimated to be $2.8 \%$ in the United States, according to the U.S. Centers for Disease Control and Prevention ${ }^{6}$.

Hang cheng et $\mathrm{al}^{7}$ in his study concluded that extended operative times across wide range of procedures almost doubled the risk of surgical site infections. In our study statistically significant effects of prolonged surgical time affecting incidence of superficial SSI was demonstrated only in patients who underwent elective laparotomy. prolonged laparotomy time was associated with 6 times increased risk of development of superficial SSI in elective laparotomies in our study.

Surgical wounds are classified into clean, clean contaminated, contaminated and dirty according to the level of microbial contamination ${ }^{8}$. our study demonstrated statistically significant increase in surgical site infections as the level of contamination increased .when clean and clean contaminated cases were pooled together and contaminated and dirty cases pooled together and analysed we demonstrated strong association between level of microbial contamination and development of SSI. Our study demonstrated a four times increased incidence of superficial SSI in contaminated and dirty laparotomy wounds.

Study by Lilani SP et $\mathrm{al}^{9}$ demonstrated a statistically significant increase in surgical site infections between clean and clean contaminated surgeries in general surgical procedures 
(3.03\%vs $22.41 \%$ P value- 0.0021 )

Ortega $\mathrm{Et} \mathrm{Al}^{10}$ demonstrated decreased incidence of superficial surgical site infection across clean (1.8\%) clean contaminated $(3.9 \%)$ contaminated $(4.8 \%)$ and $\operatorname{dirty}(5.2 \%)$ wound classifications where as our study showed increased incidence in clean $(7.1 \%)$, clean contaminated $(8 \%)$, contaminated $(35.3 \%)$ and $\operatorname{dirty}(32.3 \%)$. This higher incidence might be due to better adherence to aseptic precautions and better antibiotic policies in developed nations

\section{Conclusion}

Prolonged duration of surgery was found to increase the risk of development of superficial surgical site infections. In elective laparotomy reducing the duration of surgery by using better techniques and skilled and experienced team can largely benefit the patients.

Level of microbial contamination was demonstrated to be the single most important factor predicting the development of superficial surgical site infections. The lack of proper antibiotic policy and stricter surveillance should be pointed out as the reason for increased surgical site infections in developing nations and their introduction can contribute to the reduction of surgical site infections

\section{Bibliography}

1. Horan TC, Gaynes RP, Martone WJ, Jarvis WR, Emori TG. CDC definitions of nosocomial surgical site infections, 1992; A modification of CDC definitions of surgical wound infections. Infection Control Hosp Epidemiol. 1992; 13 606-608.

2. Centers for Disease Control and Prevention (CDC). Surgical site infection (SSI). 2016.www.cdc.gov/HAI/ssi/faq_ssi.html.

Accessed September 12, 2018.

3. Arora A, Bharadwaj P, Chaturvedi H, Chowbey P, Gupta S, Leaper D, Mani G K, S Marya S K, Premnath R, Quadros K, Srivastava A, Tendolkar A A review of prevention of surgical site infections in Indian hospitals based on global guidelines for the prevention of surgical site infection, 2016 JPSIC 2018 Volume: 6 Issue Number:1 Page: $1-12$

4. Kumar A, Rai A. Prevalence of surgical site infection in general surgery in a tertiary care centre in India. Int Surg J 2017;4:3101-6.

5. Kamat US, Fereirra AM, Kulkarni MS, Motghare DD. A prospective study of surgical site infections in a teaching hospital in Goa. Indian J Surg 2008;70:120-4.

6. Barie PS .Surgical site infections: epidemiology and prevention. Surg Infect (Larchmt)2002;3 Suppl 1:S9-21

7. Cheng H, Chen BP, Soleas IM, Ferko NC, Cameron CG, Hinoul P. Prolonged Operative Duration Increases Risk of Surgical Site Infections: A Systematic Review. Surg Infect (Larchmt). 2017;18(6):722-735.

8. Kamel C, McGahan L, Mierzwinski-Urban $M$, et al. Preoperative Skin Antiseptic Preparations and Application Techniques for Preventing Surgical Site Infections: A Systematic Review of the Clinical Evidence and Guidelines [Internet]. Ottawa (ON): Canadian Agency for Drugs and Technologies in Health; 2011 Jun. Appendix 1, Classification of surgical wounds. Available from: https://www.ncbi.nlm.nih.gov/books/NBK17 4534/

9. Lilani S P, Jangale N, Chowdhary A, Daver $G$ B. Surgical site infection in clean and clean-contaminated cases. Indian J Med Microbiol 2005;23:249-52

10. Ortega, G., Rhee, D. S., Papandria, D. J., Yang, J., Ibrahim, A. M., Shore, A. D., ... Abdullah, F. (2012). An Evaluation of Surgical Site Infections by Wound Classification System Using the ACS-NSQIP. Journal of Surgical Research, 174(1), 3338.doi:10.1016/j.jss.2011.05.056. 